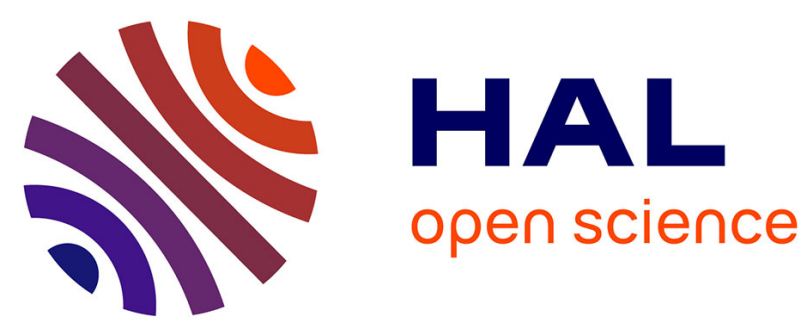

\title{
Modeling Stability of Photoheterotrophic Continuous Cultures in Photobioreactors
}

\author{
Jean-François Cornet, Lidia Favier, Claude-Gilles Dussap
}

\section{To cite this version:}

Jean-François Cornet, Lidia Favier, Claude-Gilles Dussap. Modeling Stability of Photoheterotrophic Continuous Cultures in Photobioreactors. Biotechnology Progress, 2003, 19 (4), pp.1216-1227. 10.1021/bp034041l . hal-02841877

\section{HAL Id: hal-02841877 \\ https://hal.science/hal-02841877}

Submitted on 7 Jun 2020

HAL is a multi-disciplinary open access archive for the deposit and dissemination of scientific research documents, whether they are published or not. The documents may come from teaching and research institutions in France or abroad, or from public or private research centers.
L'archive ouverte pluridisciplinaire HAL, est destinée au dépôt et à la diffusion de documents scientifiques de niveau recherche, publiés ou non, émanant des établissements d'enseignement et de recherche français ou étrangers, des laboratoires publics ou privés. 


\title{
Modeling Stability of Photoheterotrophic Continuous
}

\section{Cultures in Photobioreactors}

\author{
Jean-François CORNET*, Lidia FAVIER, Claude-Gilles DUSSAP \\ Laboratoire de Génie Chimique et Biochimique. Université Blaise Pascal - CUST \\ 24, avenue des Landais, BP 206. F 63174 AUBIERE Cedex. France
}

J-Francois.CORNET@univ-bpclermont.fr

Phone: (33) 4.73.40.50.56. Fax: (33) 4.73.40.78.29.

\begin{abstract}
Continuous cultures of the purple non-sulfur bacterium Rhodospirillum rubrum were grown in a cylindrical photobioreactor in photoheterotrophic conditions, using acetate as carbon source. A new kinetic and stoichiometric knowledge model was developed and its ability to simulate experimental results obtained under varying incident light fluxes and residence times is discussed. The model
\end{abstract}


accurately predicts the stable, unstable or oscillating behavior observed for the reactor productivity. In particular, the values of residence time corresponding to a sub-critical bifurcation with a typical hysteresis effect are calculated and analyzed. The robustness of the proposed model allows the engineering operating domain of the photobioreactor function to be set, and offers a promising tool for the design and control of such photoheterotrophic processes.

\section{INTRODUCTION}

Purple non-sulfur bacteria (Rhodospirillaceae) are very promising tools for many industrial purposes, especially when cultivated in photoheterotrophic conditions in closed, artificially illuminated and fully controlled photobioreactors (PBRs). Among a wide variety of processes, their main applications include waste-water treatment of industrial effluents (1) and recycling wastes in closed artificial ecosystems such as MELiSSA (Micro-Ecological Life Support System Alternative) (2), the ecosystem studied by the European Space Agency as a basic model for long-term space missions and planet outposts. The production of biodegradable polymers such as $\beta$-polyhydroxybutyrate (PHB) (3-6), the production of single cell proteins or high-value products (7-9) such as pigments, growth factors, chemical entities of therapeutic interest, and the photo-production of hydrogen (10-12) are also potential applications of purple bacteria cultures.

The control, design and optimization of PBRs used to cultivate such microorganisms in photoheterotrophic conditions requires accurate modeling. The framework of a knowledge model for a PBR presupposes a proper representation of light energy availability, which in turn requires formulating the radiative transfer in vessels of given geometry, and then coupling with stoichiometry, local kinetics and mean volumetric biological synthesis rates (Figure 1). 


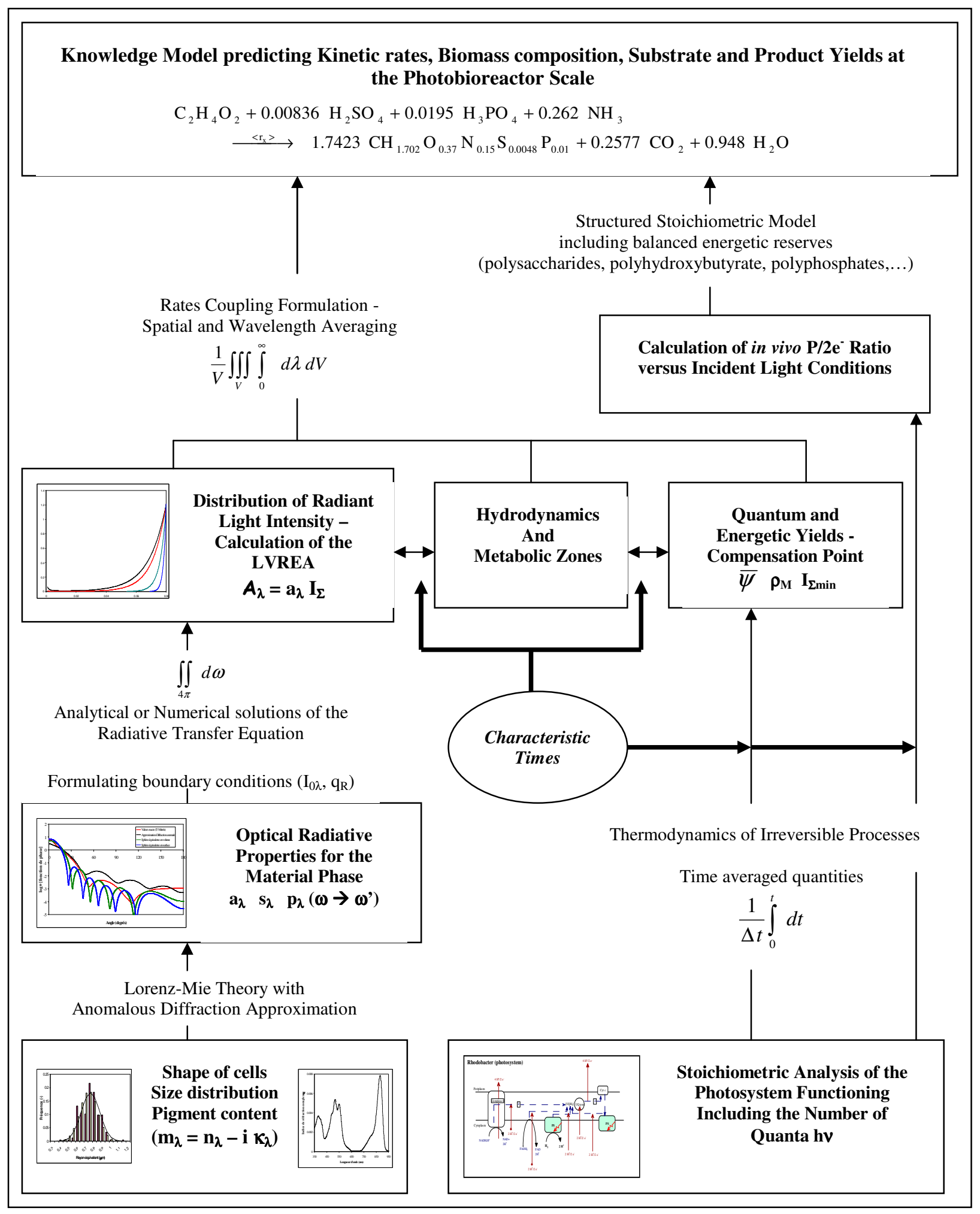

Figure 1. How to build a knowledge model for photobioreactors with respect to scale and time characteristics: managing a seven-dimensional Euclidean space. 
Because of its relative simplicity, the description of the highly heterogeneous light transfer process in dense microalgal media is currently approximated by Bouguer's law (improperly called Lambert's law), which neglects scattering of light by micro-organisms inside the reactor (13-18). However, for low light transmittances, this law may underestimate locally available light energy by several orders of magnitude, and so a more accurate description is needed for this physical process (19-21). The solution of the radiative transfer equation (RTE) makes it possible accurately to calculate the local light intensity inside the PBR, but entails highly complicated mathematical and computational developments. A compromise must therefore be found between full three-dimensional treatment of the RTE by Monte Carlo methods (22) or finite element methods (23), and the simplicity but inaccuracy of Bouguer's law. If a symmetry arises from the mathematical analysis, the compromise consists in using the one-dimensional form of the RTE $(19-21,24)$, if the radiative optical properties for the micro-organisms can be estimated, i.e., the so-called absorption and scattering coefficients with the phase function for scattering (24).

Formulating the coupling between radiant light transfer and biological rates first requires the definition of a local kinetic law for biomass growth rate from the local available radiant energy distribution in the reactor. This must then be averaged, with or without the definition of different kinetic zones, to obtain the observable mean volumetric rates in the PBR. During the last decades, many more or less empirical kinetic laws have been proposed and are still being debated, as recently reviewed and discussed by Muller-Feuga et al. (25). However, it is possible to arrive at a better understanding of the coupling through an energetic-based approach, using irreversible-process thermodynamic analysis of the photophosphorylation and reducing power synthesis in the electron transport chains, and then of their conversion into main cellular components $(21,26)$.

This paper presents a new knowledge model for the growth of the purple non-sulfur bacterium Rhodospirillum rubrum, cultivated in a cylindrical radially-illuminated photobioreactor operating in 
continuous and photoheterotrophic modes with acetate as carbon source. The approach described is novel and innovative in that (Figure 1):

- a generalized two-flux method is used to solve the RTE in the PBR with exact optical radiative properties for Rs. rubrum, theoretically calculated by the Lorenz-Mie theory $(27,28)$;

- energetic yields are used to formulate the coupling between the available light energy and kinetic rates, their theoretical value being calculated by thermodynamic analysis of the photoheterotrophic functioning of the photosystem;

- a zone model is presented and a working illuminated volume is defined in the PBR, reconciling local cellular energetic and mean volumetric kinetic rates $(20,21,24)$;

- a stoichiometric approach takes into account the PHB storage in the cells for any condition of PBR illumination.

The obtained knowledge model, requiring only one experimental coefficient determination for rate calculation, is then used to explain the wide variety of PBR regimes observed by varying incident light flux and liquid flow rate of the feed in continuous mode. Special attention has been paid to the analysis of the stability conditions for the PBR function, and to the definition of an operating domain for the main process variables.

\section{MATERIALS AND METHODS}

\section{Culture conditions}

Rhodospirillum rubrum ATCC 25903 was cultivated in the basal salt medium of Segers \& Verstraete (29) as described by Suhaimi et al. (30) with acetate and ammonium chloride as C and N sources, and biotin as the only vitamin. Acetate and $\mathrm{NH}_{4}{ }^{+}$were adjusted to avoid $\mathrm{C}$ and $\mathrm{N}$ limitation in the PBR, 
keeping a $\mathrm{C} / \mathrm{N}$ ratio of 3. A phosphate buffer was used $\left(0.49 \mathrm{~g} \mathrm{~L}^{-1} \mathrm{KH}_{2} \mathrm{PO}_{4}\right.$ and $\left.0.52 \mathrm{~g} \mathrm{~L}^{-1} \mathrm{~K}_{2} \mathrm{HPO}_{4}\right)$, and pH was adjusted to 6.9 .

Rs. rubrum was grown in a stirred, cylindrical, radially illuminated photobioreactor (radius $0.08 \mathrm{~m}$ ) containing $5 \mathrm{~L}$ of culture media. A $10 \%$ (vol.) inoculum was used. Temperature and $\mathrm{pH}$ were maintained automatically at $30^{\circ} \mathrm{C}$ and 7 using respectively a coiled heat exchanger and a 2 mol L ${ }^{-1} \mathrm{H}_{2} \mathrm{SO}_{4}$ solution. Stirring was set at $400 \mathrm{rpm}$ using two rushton impellers of $6 \mathrm{~cm}$ diameter, and argon was introduced at 4 $\mathrm{L} \mathrm{h}^{-1}$ to maintain anoxygenic conditions. A continuous artificial illumination was provided by 55 halogen lamps (Sylvania professional $25 \mathrm{BAB} 38^{\circ}, 12 \mathrm{~V}, 20 \mathrm{~W}$ ) arranged around the reactor. Illumination of the culture was controlled by adjusting the power supplied to the lamps. Light incident fluxes were calibrated from a method described elsewhere (31).

All the experiments were carried out in continuous mode with different residence times, and the incident light flux $q_{R}$ was varied between 50 and $400 \mathrm{~W} \mathrm{~m}^{-2}$ [350-950 nm]. Samples were taken periodically from the output flow to analyze the changes in the system until a steady state was obtained. At steady state, dry weight, acetate and acetoacetate concentrations, pigment, protein, total carbohydrate and poly- $\beta$-hydroxybutyric acid (PHB) contents were determined. All the experimental results given at steady state were averaged over at least six residence times in the PBR. The $\mathrm{CO}_{2}$ mole fraction in the output gas phase of the reactor was continuously analyzed using a $\mathrm{CO}_{2}$ infrared analyzer (ADC, England). The dissolved $\mathrm{CO}_{2}$ was quantified by applying the gas mass balance on the reactor from the knowledge of the volumetric $\mathrm{CO}_{2}$ gas-liquid mass transfer coefficient preliminary determined.

\section{Analytical procedure}

Acetate and acetoacetate in the culture medium were assayed by HPLC analysis. The chromatograph (Agilent 1100, Agilent Technologies, Palo Alto, CA, USA) was fitted with two ion exclusion columns 
(Resex ROA 300 x 7.8 mm, Phenomenex, Torrance, CA, USA) mounted in series. Bacteriochlorophyll $a$ and carotenoids in the biomass were estimated from the absorbances at 880,515 and $720 \mathrm{~nm}(32)$ of a sonicated cell suspension after applying a correction to take into account light scattering by cells in the sample. The PHB content was determined by GC using the method developed by Braunegg et al. (33). Analysis were performed on a polar supelco 2-4084 (Supelco. Inc., Bellefonte, PA) capillary column (30 $\mathrm{m} \times 0.32 \mathrm{~mm})$, with a flame ionisation detector. Nitrogen was used as carrier gas $\left(1.7 \mathrm{~mL} \mathrm{~min}{ }^{-1}\right)$ and caproic acid as internal standard. Total protein content was determined by the method of Lowry after hydrolysis of samples in $\mathrm{NaOH}$. Total carbohydrate content was determined according to the phenol method of Herbert et al. (34).

The elemental analysis of biomass $(\mathrm{C}, \mathrm{H}, \mathrm{O}, \mathrm{N}, \mathrm{S}, \mathrm{P})$ was carried out at CNRS Vernaison (France) for each run at steady state.

For all the experimental results reported and discussed in this paper, the carbon recovery percentage (CRP) defined as the mass ratio of total carbon in the output flows of the reactor over the total carbon in the input flows of the reactor was $100 \pm 10 \%$.

\section{KINETIC MODELING}

\section{Radiant Light Transfer}

The quasi-steady-state equation of radiative transfer for a non-emitting participating medium (with $a$ and $s$ respectively the volumetric absorption and scattering coefficients)

$$
\mathbf{u} \cdot \nabla I=-(a+s) I+\frac{s}{4 \pi} \iint_{4 \pi} I \cdot p\left(\mathbf{u}, \mathbf{u}^{\prime}\right) d \omega
$$

over a given interval of wavelength, may be solved in one-dimensional geometries, applying the generalized 2-flux method $(35,36)$. The assumption is made that a semi-isotropic intensity distribution 
exists (and not necessarily an isotropic phase function as for the Schuster-Schwarzchild approach (37)), allowing the integral in Equation (1) to be solved for azimuthally symmetric radiation. Thus, the integration on each hemisphere gives the following set of equations in cylindrical coordinates (20):

$$
\left\{\begin{array}{l}
\frac{1}{r} \frac{\partial}{\partial r}\left(r q_{r}^{+}\right)=-(\hat{a}+\widehat{s}) q_{r}^{+}+\widehat{s} q_{r}^{-} \\
\frac{1}{r} \frac{\partial}{\partial r}\left(r q_{r}^{-}\right)=(\widehat{a}+\widehat{s}) q_{r}^{-}+\widehat{s} q_{r}^{+}
\end{array}\right.
$$

in which the radiative flux $\mathbf{q}$ is defined by the integral over all the directions (solid angle $\omega$ ) $\mathbf{q}=\iint_{4 \pi} I \cos \theta d \omega$ and the total radiant energy available $I_{\Sigma}$ by $I_{\Sigma}=\iint_{4 \pi} I d \omega$. The $\hat{a}$ and $\hat{s}$ quantities denote hemispherically integrated values defined by:

$$
\begin{aligned}
& \widehat{a}=2 a=2 E a C_{X} \\
& \widehat{s}=2 b s=2 b E s C_{X}
\end{aligned}
$$

in which the back-scattered fraction $b$ is evaluated from the generalized Lorenz-Mie theory (giving $\mu=\cos \theta)$ by the double integral of the phase function $p(35,36)$ :

$$
b=\int_{0}^{1} \int_{-1}^{0} p\left(\mu, \mu^{\prime}\right) d \mu^{\prime} d \mu
$$

These mean optical radiative properties for Rhodospirillum rubrum (Eq. 3-4) were calculated in the range of wavelength $[350-950 \mathrm{~nm}]$, and are given in Table 1. For this purpose, we assumed that Rs. rubrum was equivalent to a long cylinder with a log-normal size distribution law and we used the anomalous diffraction approximation proposed by Van de Hulst (27).

The resolution of the system of Equations (2) with the appropriate boundary conditions corresponding to a mean homogeneous radial incident flux at $\mathrm{R} q_{R}^{+}=q_{R}$ then gives: 


$$
\frac{I_{\Sigma r}}{q_{R}}=\frac{R}{r} \frac{4 \cosh (\delta r)}{\cosh (\delta R)+\alpha \sinh (\delta R)}
$$

yielding the profile of total available radiant energy $I_{\Sigma}$ versus the radius $r$ of the photobioreactor, knowing

$$
\begin{aligned}
& \alpha=\sqrt{\frac{\widehat{a}}{\hat{a}+2 \widehat{s}}} \\
& \delta=\sqrt{\hat{a}(\hat{a}+2 \widehat{s})}
\end{aligned}
$$

\section{Coupling Light Transfer with Local and Spatial Kinetic Rates}

\section{Local coupling}

The local volumetric growth rate $r_{X}$ is easily deduced from the Local Volumetric Rate of radiant Energy Absorbed $\boldsymbol{A}$ (LVREA) applying two conversion yields:

$$
r_{X}=\rho \bar{\psi} A=\rho \bar{\psi} a I_{\Sigma r}
$$

First, the mean mass stoichiometric quantum yield $\bar{\psi}$ (i.e., calculated from a mean wavelength in the considered range [350-950 nm] and for a given emission spectrum of the lamps) appears quasi-constant in regard to radiant light energy changes. The bar indicates a time-averaged value on the metabolism so as to be able to apply the relations of the thermodynamics of irreversible processes (TIP) in the yield calculation $(21,26)$, or a metabolic flux network approach (38). Considering the mixing time in the PBR as a few seconds (corresponding to the mean time for cells to gather in all the existing local intensities in the PBR, or a cycle time), it is clear that the environmental relaxation time (some milliseconds) is much smaller than the considered relaxation time for applying TIP (a minute, 26, 39), and hence, the metabolism inside the cells can be safely considered as frozen with respect to the dynamics of change in 
radiant light energy conditions. Consequently, these latter mechanisms can be removed from the dynamic description of the system (40) justifying the choice of the thermodynamic relaxation time in averaging $\bar{\psi}$. Also, if we compare the TIP relaxation time with the characteristic dynamics for growth (a few hours), it is clear that the main reactions involved in the thermodynamic analysis of photosynthesis can be considered as operating at pseudo-steady-state, justifying this approach $a$ posteriori.

Conversely, the energetic yield $\rho$ roughly corresponding to the primary efficiency of electron transfer in photosynthetic antennas is strongly dependent on the total available radiant light energy $I_{\Sigma}$, and so appears as a local quantity, giving a physical basis to the definition of a local kinetic rate $r_{X}$. The maximum value of this yield $\rho_{M}$ appears at the compensation point for photosynthesis and may be calculated from a thermodynamic treatment of the radiant energy conversion process, which is still a problem under debate $(41,42)$. However, a theoretical calculation of the law for changes with available radiant light energy is today an unrealistic challenge, despite tentative analysis (43), and one can postulate a law in the form:

$$
\rho=\rho_{M} \frac{K}{K+I_{\Sigma}}
$$

giving with Equation (6) and explaining the LVREA, a well-known hyperbolic behavior for growth:

$$
r_{X}=\rho_{M} \bar{\psi} E a C_{X} K \frac{I_{\Sigma}}{K+I_{\Sigma}}
$$

The calculated coefficients for the local volumetric biomass growth rate are given in Table 1, and the sole coefficient experimentally identified is then the half saturation constant for light $K$. 


\section{Spatial coupling}

The calculation of the mean spatial growth rate $\left\langle r_{X}>\right.$ is obtained in accordance with our previous analysis (44). This approach postulates that there may exist an efficient dark zone in the PBR in which, nevertheless, the rate is set by the physical light driven process occurring inside the working illuminated volume. This assumption is supported at the metabolic level by the existence of the reverse electron transfer $(\mathrm{RET})$ mechanism, enabling the synthesis of reducing power $\left(\mathrm{NADH}_{2}\right)$ for short dark residence time. In the general case (physical limitation by light transfer), the total volume of the reactor is then divided into three parts:

- a dark volume $V_{l}$ in which no growth occurs when the residence time is not too long to allow that a new metabolism to take place $\left(r_{X I}=0\right)$;

- a volume $V_{2}$ ( $\beta$ fraction) corresponding to the dark operative zone in the PBR with a mean rate set by the illuminated zone;

- a volume $V_{3}$ ( $\gamma$ fraction) corresponding to the working illuminated volume in which the local rates $r_{X 3}$ are given by Equation (8).

The mean growth rate is then given by:

$$
<r_{X}>=(1-\beta-\gamma) \frac{1}{V_{1}} \iiint_{V_{1}} r_{X 1} d V+\beta \frac{1}{V_{2}} \iiint_{V_{2}} r_{X 2} d V+\gamma \frac{1}{V_{3}} \iiint_{V_{3}} r_{X 3} d V
$$

with $r_{X I}=0$. From the previous hypothesis on the dark operative volume, $\frac{1}{V_{2}} \iiint_{V_{2}} r_{X 2} d V=\frac{1}{V_{3}} \iiint_{V_{3}} r_{X 3} d V$, and taking into account the possibility of having only an illuminated surface fraction $f_{I}$ on the PBR, one obtains:

$$
<r_{X}>=f_{I}(\beta+\gamma) \frac{1}{V_{3}} \iiint_{V_{3}} r_{X 3} d V
$$


Comparisons of Equation (9) with different experimental results in cylindrical PBR led to the simple (and expected ?) result that it was necessary to choose $\beta=\gamma$. The final formula giving the mean growth rate is then:

$$
<r_{X}>=f_{I} 2 \gamma \frac{1}{V_{3}} \iiint_{V_{3}} r_{X 3} d V
$$

This formula is correct only if $\gamma \leq 0,5$ (physical limitation by light transfer); otherwise, Equation (9) applies with $\beta+\gamma=1(\beta \leq 0,5)$, showing that in physical limitation, the PBR is twice more efficient as in the kinetic regime $\left(\gamma=1 ; V_{3}=V_{T}\right)$.

In both cases, the working illuminated volume $V_{3}$ is defined considering the minimal radiant light energy available for photosynthesis $I_{\Sigma \min }($ Table 1 ), independently determined from the appearance of the linear behavior of batch cultures $(19,44)$. In the case of the one-dimensional approximation for the radiant light transfer (Eq. 5), the volume integral in Eqs. (9-10) reduces to a simple integral in which the working illuminated volume is only determined from the calculation of the radial illuminated part of the $\operatorname{PBR}(20,21)$.

Table 1. Numerical values of the coefficients for the mathematical knowledge model. The considered spectrum is $[350-950 \mathrm{~nm}]$.

\begin{tabular}{|l|}
\hline $\begin{array}{l}E a=15000 w_{P I G} \mathrm{~m}^{2} \mathrm{~kg}^{-1} \\
\text { where } w_{P I G} \text { is given by Equation (12) in text }\end{array}$ \\
\hline$E s=200 \mathrm{~m}^{2} \mathrm{~kg}^{-1}$ \\
\hline$b=0.105[$ dimensionless] \\
\hline $\bar{\psi}=2.610^{-8} \mathrm{~kg} \mathrm{~J}^{-1}$ \\
\hline$\rho_{M}=0.706[$ dimensionless $]$ \\
\hline$K=25 \mathrm{~W} \mathrm{~m}^{-2}$ \\
\hline$I_{\Sigma \min }=0.6 \mathrm{~W} \mathrm{~m}^{-2}$ \\
\hline
\end{tabular}


Importantly, it must be noticed that the previous hypothesis taking $\beta=\gamma$ is not independent of the hydrodynamics, or roughly speaking, of the mixing time in the PBR. Clearly, the cycle time or the light/dark exposure frequency in the completely stirred tank reactor may affect the biomass productivity, specially if a dark efficient zone exists (the $\beta$ fraction) in heterotrophic conditions. This point has been investigated showing that the light-limited productivities were impaired to some extent if a minimum rotation speed (i.e. a maximum mixing time) was not respected in the PBR, invalidating in these cases the $\beta=\gamma$ assumption. Because this discussion will require further lengthy developments, we limited this paper to results for which the best mixing conditions were satisfied, i.e. as previously stated, to experiments with a rotation speed of at least $400 \mathrm{rpm}$.

\section{Additional laws for metabolic changes}

At the present time, it is not possible to present a complete TIP analysis for Rs. rubrum as was done for Spirulina (21). Consequently, we are unable to provide a general predictive law for the theoretical calculation of the $P / 2 e^{-}$ratio in the cell, or for the calculation of the key energetic balanced synthesized metabolite versus the incident light flux (21). For Rs. rubrum, this key metabolite is clearly the poly- $\beta$ hydroxybutyrate which accumulates inside the cells (45) when the incident light flux $q_{R}$ is varied. Based on previous experimental results, we propose the following relationship to take into account changes in the mole fraction of PHB versus the incident light flux:

$$
x_{P H B}=0.3 \ln \left(1+\frac{q_{R}}{100}\right)
$$

The choice in relating the mole fraction to a general spatial information item (the incident radiant flux $\left.q_{R}\right)$ rather than a local variable in the PBR relies on the assumptions already discussed to apply the TIP to the metabolism of the micro-organism. This approach is validated by the numerous experimental 
results obtained for the exopolysaccharide content in Spirulina platensis cultivation (21). Also, the general form of the law (11) has a physical basis in defining light averaged spatial values in the PBR (not yet published). This makes it possible to calculate the PHB content in the total biomass and then establish the global stoichiometry as presented in the next section. This stoichiometry defines the yields for substrates and products, and then their respective molar rates, in particular for the $\mathrm{CO}_{2}$ evolution.

At the same time, because there exists a very complex regulation of the Rhodospirillum photosystem by the pigment content, we need to be able to take into account the metabolic deviations occurring, especially in the bacteriochlorophyll $a$ content, when the degree of light limitation (the working illuminated fraction $\gamma$ ) is varied. These changes have no effect on global stoichiometry, but the pigment content is strongly involved in the definition of the absorption coefficient for light (Equation 3), and therefore in the radiative transfer description. From the experimental results obtained from varying $q_{R}$ and the biomass concentration $C_{X}$ in a broad domain, we can suppose that for a low value of the illuminated fraction $\gamma$ in the PBR (strong light limitation), the pigment content remains constant in the active biomass, and so it decreases with the incident light flux increasing the PHB content (Eq. 11). This is gradually modulated as $\gamma$ approaches 1 (in a kinetic regime) for which the pigment content appears independent of $q_{R}$ and constant at its minimal value (1\%). The law for the mass pigment fraction in the cells $w_{P I G}$ then takes the following form (for $0<q_{R}<400 \mathrm{~W} \mathrm{~m}^{-2}$ ):

$$
w_{P I G}=\frac{2.4\left(1-w_{P H B}\right)-\left(1.4-2.4 w_{P H B}\right) \gamma}{100}
$$

where $w_{P H B}$ is the mass fraction for PHB in the total biomass, calculated from Equation (11). The illuminated fraction $\gamma$ appears here as the main lumped parameter to formulate the coupling between the mass pigment content and the radiant light transfer. The value of the mass absorption coefficient $E a$ 
versus the incident light flux onto the PBR $q_{R}$ is then easily calculated by direct proportionality from Eqs. (11-12) (Table 1).

This relation shows that there is no dependence for $E a$ when the PBR is entirely illuminated $(\gamma=1 ; w$ $=0.010)$, as experimentally confirmed in the domain $\left[50-400 \mathrm{~W} \mathrm{~m}^{-2}\right]$, and that the pigment content is also minimum at very high light flux $\left(400 \mathrm{~W} \mathrm{~m}^{-2}\right)$ for any value of $\gamma$.

\section{Spatial Mass Balances}

The dynamic or steady-state behavior of the total biomass concentration is then calculated applying the overall mass balance on the PBR (considered as a completely stirred tank reactor with a residence time $\tau$ ) and assuming that there is no biomass in the feed:

$$
\frac{d C_{X}}{d t}=<r_{X}>-\frac{C_{X}}{\tau}
$$

A Fortran code was developed to find the steady state solutions of Eq. (13), with Equations (3-12) for the calculation of the mean biomass volumetric growth rate, and to study their stability. It must be pointed out that the described kinetic model presents a high degree of non-linearity, and so finding the numerical solutions of Eq. (13) near the steady state is arduous, especially for high biomass concentrations, and may become highly CPU time consuming.

\section{STOICHIOMETRIC MODELING ON ACETATE}

From elemental analysis on biomass obtained in precultures, the elemental formula for active biomass of Rhodospirillum rubrum ATCC 25903 (i.e. without intracellular PHB) was established as:

$$
\mathrm{CH}_{1.75} \mathrm{O}_{0.34} \mathrm{~N}_{0.188} S_{0.006} P_{0.014}
$$


Consequently, in regular culture conditions (i.e. without excretion of acetoacetate nor polyphosphate accumulation in the cells), the stoichiometric equation for the growth of Rs rubrum in any condition of intracellular PHB content (mole fraction $x$ ) is:

$$
\begin{aligned}
& \mathrm{C}_{2} \mathrm{H}_{4} \mathrm{O}_{2}+a \mathrm{H}_{2} \mathrm{SO}_{4}+b \mathrm{H}_{3} \mathrm{PO}_{4}+c \mathrm{NH}_{3}
\end{aligned}
$$

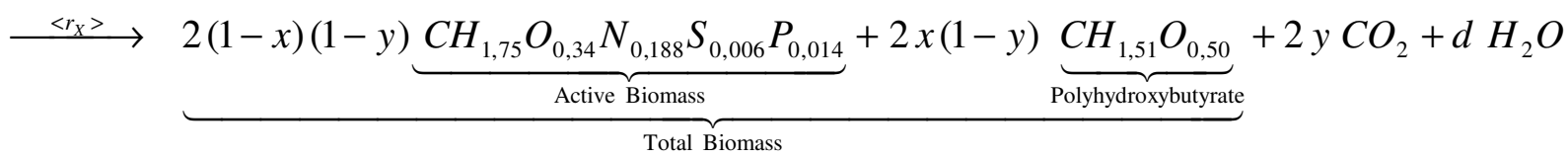

$y$ corresponds to the mole fraction of produced carbon which is released as $\mathrm{CO}_{2} ; x$ is the mole fraction of PHB in the total biomass, depending only of the radiant incident light flux onto the PBR as mentioned above (Eq. 11). If the PHB content $x$ is known, the coefficients reduction of Eq. (14) with no degree of freedom is straightforward:

$$
\begin{aligned}
& y=\frac{0.612-0.102 x}{4.612-0.102 x} \\
& a=2(1-x)(1-y) 0.006 \\
& b=2(1-x)(1-y) 0.014 \\
& c=2(1-x)(1-y) 0.188 \\
& d=2-0.52(1-x)(1-y)-4 y-x(1-y)
\end{aligned}
$$

The total biomass elemental formula is then easily calculated from: $C H_{Z_{H}} O_{Z_{O}} N_{Z_{N}} S_{Z_{S}} P_{Z_{P}}$, with:

$$
\begin{aligned}
Z_{H} & =\frac{2(1-x)(1-y) 1.75+2 x(1-y) 1.51}{2(1-x)(1-y)+2 x(1-y)} \\
Z_{O} & =\frac{2(1-x)(1-y) 0.34+2 x(1-y) 0.5}{2(1-x)(1-y)+2 x(1-y)} \\
Z_{N} & =\frac{2(1-x)(1-y) 0.188}{2(1-x)(1-y)+2 x(1-y)} \\
Z_{S} & =\frac{2(1-x)(1-y) 0.006}{2(1-x)(1-y)+2 x(1-y)} \\
Z_{P} & =\frac{2(1-x)(1-y) 0.014}{2(1-x)(1-y)+2 x(1-y)}
\end{aligned}
$$


giving the final stoichiometry. For example, with a PHB content $x=0.2$, one has:

$$
\begin{aligned}
\mathrm{C}_{2} \mathrm{H}_{4} \mathrm{O}_{2} & +0.00836 \mathrm{H}_{2} \mathrm{SO}_{4}+0.0195 \mathrm{H}_{3} \mathrm{PO}_{4}+0.262 \mathrm{NH}_{3} \\
& \stackrel{<r_{x}>}{\longrightarrow} 1.7423 \mathrm{CH}_{1.702} \mathrm{O}_{0.37} \mathrm{~N}_{0.15} \mathrm{~S}_{0.0048} P_{0.01}+0.2577 \mathrm{CO}_{2}+0.948 \mathrm{H}_{2} \mathrm{O}
\end{aligned}
$$

Finally, the mass conversion yield for acetate $Y_{X / S}$ is also obtained by:

$$
Y_{X / S}=[2(1-x)(1-y)+2 x(1-y)] \frac{\left[12+Z_{H}+16 Z_{O}+14 Z_{N}+32 Z_{S}+31 Z_{P}\right]}{60}
$$

This analysis allows the calculation of the rates of consumption of substrates or the rates of product evolution providing $\left\langle r_{X}\right\rangle$ is known from the kinetic part of the model. It will be extensively used for comparison with the experimental results described below.

\section{RESULTS AND DISCUSSION}

\section{Analysis of the first critical mode}

In continuous mode and at constant incident light flux $q_{\mathrm{R}}$, the degree of light limitation (the $\gamma$ fraction) is easily modified in the PBR by varying the residence time $\tau$ (Eq. 13). At short residence times, the biomass concentration and the productivity are low and the PBR operates in kinetic mode, i.e., the incident light is in excess and the whole culture volume is illuminated $(\gamma=1)$. The PBR function then displays stable behavior which is clearly represented on Figure 2 by model calculation at an incident light flux $q_{R}$ of $100 \mathrm{~W} \mathrm{~m}^{-2}$ with a residence time $\tau$ ranging between $4 \mathrm{~h}$ (washing out limit) and $9 \mathrm{~h}$. This stable branch is confirmed by the experimental result obtained at steady state for $\tau=8.8 \mathrm{~h}$ (Fig. 2). At a critical residence time value $\tau_{\min }\left(\tau_{\min }=9 \mathrm{~h}\right)$ or higher, the steady state biomass concentration increases, so that $\gamma$ decreases, and the kinetic regime is no longer satisfied in the PBR. The model calculations (solid line) show a twofold increase in productivity (Fig. 2). This corresponds to the appearance of a 
physical limitation by light energy transfer rate, only characterized by the incident light flux $q_{R}$ and the specific illuminated area of the PBR. In these cases, the illuminated fraction $\gamma$ is lower than 0.5 and the reactor productivity is given by Eq. (10). This functioning is stable as confirmed by the experimental values obtained at $\tau=11.2 \mathrm{~h}$ and $23.8 \mathrm{~h}$ respectively (Fig. 2). This is an illustration of the efficiency of the intermediate dark zone ( $\beta$ fraction, Eq. 9) enabling highest productivities only in conditions of physical limitation by light energy transfer. As previously discussed in the model section, the gain in productivity, depending of the importance of the dark efficient zone ( $\beta$ fraction) is strongly related to the mixing time in the PBR. Moreover, mixing time values have been invoked as a justification in formulating the coupling between light transfer and kinetic rates. Independent experiments were conducted for hydrodynamic characterization of the used PBR (46) showing a very good agreement with the correlation proposed by Nagata (47), then enabling to use the relation $N . t_{m}=25$ to calculate the mixing time $t_{m}$ in any condition of rotation speed $N$ with a confidence interval of ten percents. As preliminary explained, all the experiments reported in this paper were led at $400 \mathrm{rpm}$ in order to satisfy the assumption $\beta=\gamma$ (the highest value for $\beta$ ) for the dark efficient zone in the PBR. In this case, the mixing time is found to about four seconds, corresponding to a cycle time for cells and enabling to calculate the mean residence time of cells in light and darkness during a cycle, or the light/dark exposure frequency. These results are easily obtained indeed from the calculation of the working illuminated fraction $\gamma$ in the PBR at a given steady state concentration and incident light flux. Table 2 summarizes the results, showing that, at the opposite of the conclusions recently published for an autotrophic air-lift PBR (48), the frequency of light exposure has no effect on the productivity in light-limited conditions if a sufficient short threshold cycle time is respected by mixing. 


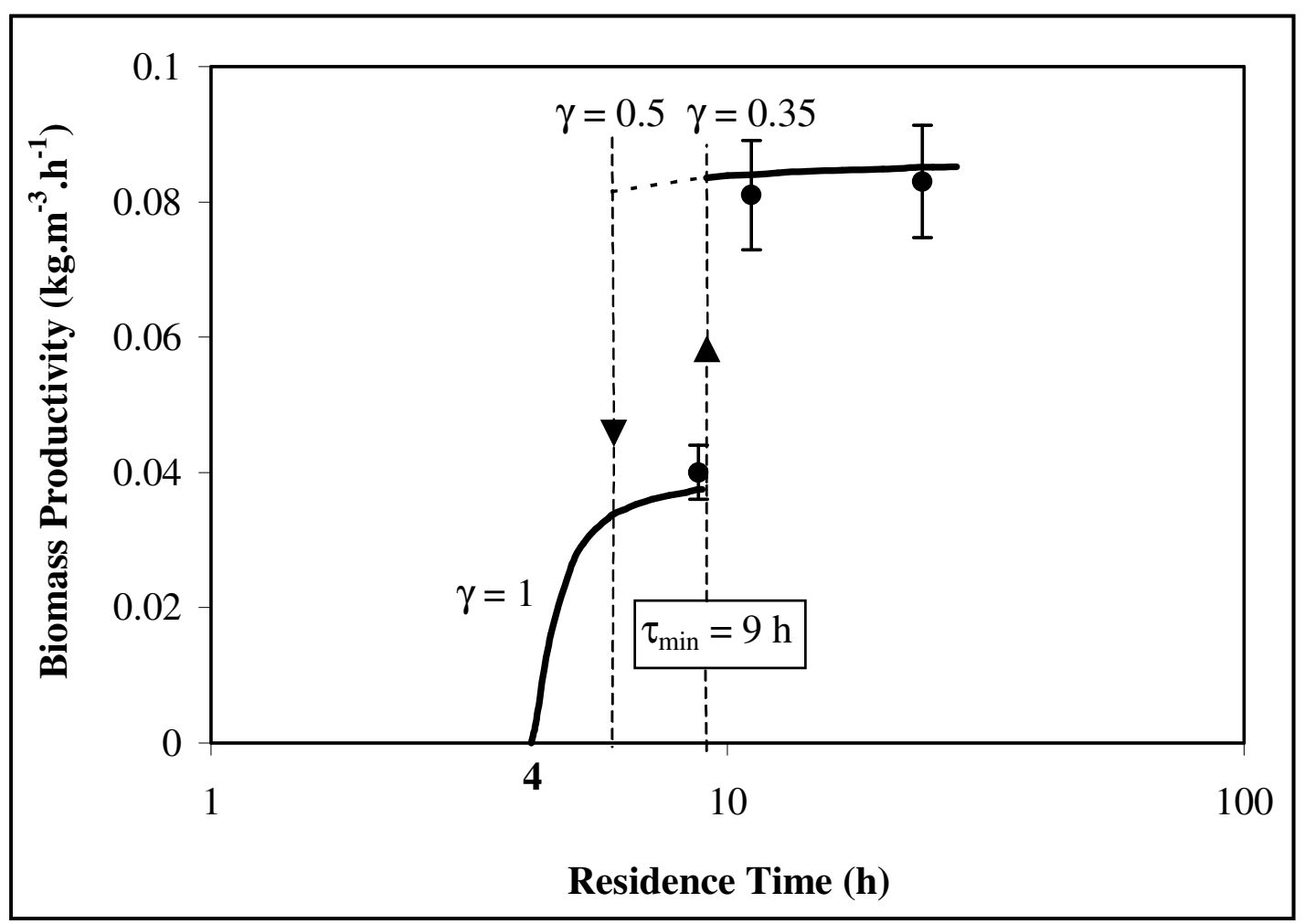

Figure 2. Comparison between experimental and model biomass productivities obtained in a photobioreactor illuminated at $q_{R}=100 \mathrm{~W} \mathrm{~m}^{-2}$ and operating in continuous mode with ranging residence time (logarithmic scale). The critical residence time $\tau_{\min }$ between kinetic and light-limited regimes is indicated, together with the particular values for the illuminated fraction $\gamma$ in the PBR, corresponding to the hysteresis effect for the unstable domain (sub-critical bifurcation).

( — ) Stable functioning for the PBR; ( - - - ) Unstable domain; (•) Experiment

Finally, between $6 \mathrm{~h}$ and $9 \mathrm{~h}$ of residence time, model calculations show, surprisingly, that two regimes may coexist (two different numerical solutions can be obtained by Eq. 13); a low productivity in kinetic regime with $\gamma=1$, and a high productivity in light-limited conditions with $\gamma \leq 0.5$. For this latter case, the first point solution of Eq. (13) appears at a critical value of $\tau_{\min }^{\prime}=6 \mathrm{~h}$ for the residence time, corresponding exactly to a value for the illuminated fraction $\gamma$ of 0.5 . This demonstrates that it is not possible to obtain steady state solutions in continuous cultures with values of $\gamma$ ranging between 0.5 and 
1, whereas these conditions are generally encountered in batch culture conditions. Moreover, experimental results have demonstrated that this branch (dotted line in Fig. 2) was unstable and led rapidly to the washing out of the PBR.

Table 2. Assessment of light exposure times $\left(t_{l}\right)$ and dark inefficient exposure times $\left(t_{d}\right)$ during a cycle time in the photobioreactor at $400 \mathrm{rpm}$. The different conditions for incident light flux $q_{R}$ and biomass concentration $C_{X}$ are respectively indicated for each experiment.

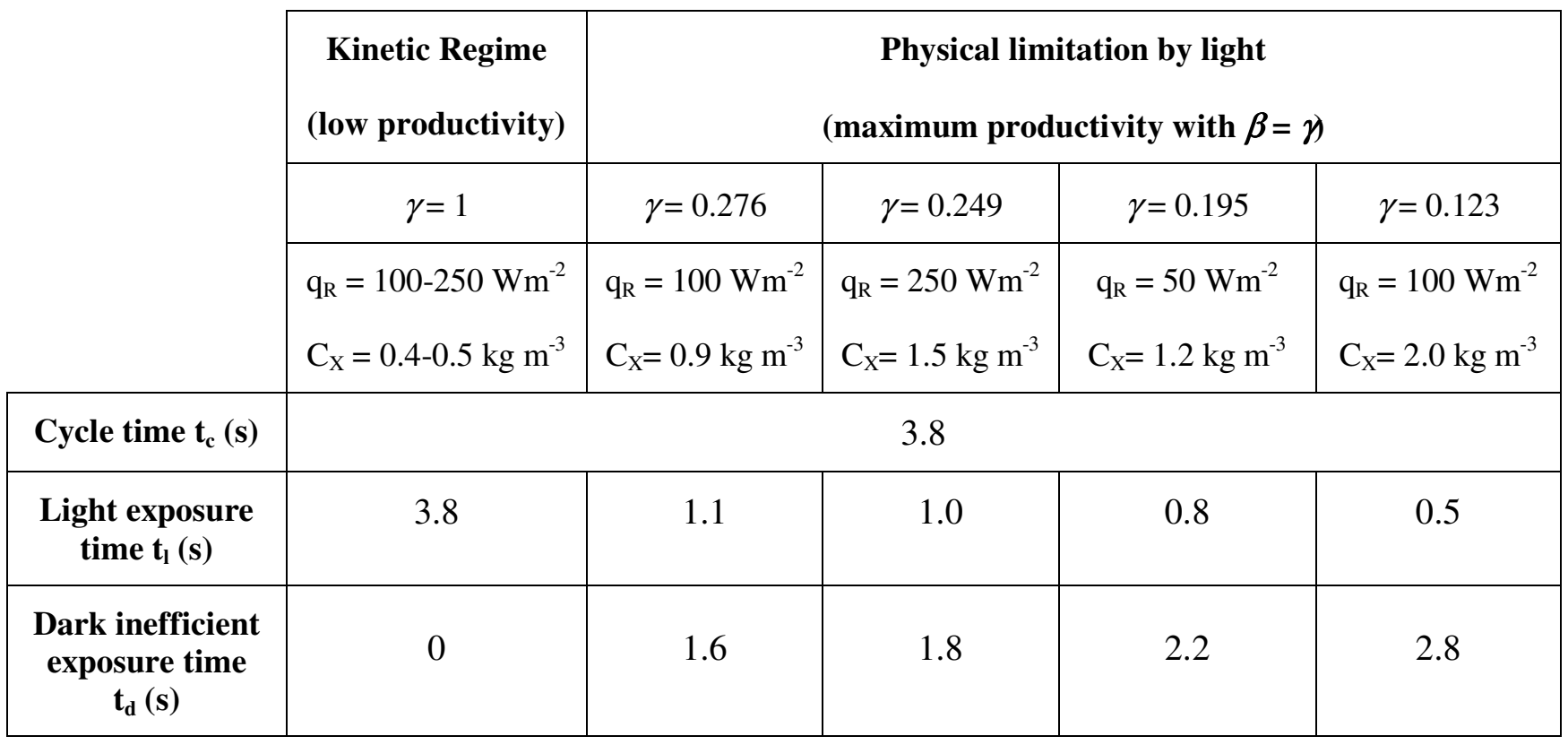

This behavior may be clarified by the so-called nonlinear dynamics theory. At the critical residence time $\tau_{\min }$, the appearance of a limit cycle with a finite amplitude (a trivial steady-state solution of Eq. 13 exists with $C_{X}=\left\langle r_{X}>=0\right.$ ); no marginal stability at the bifurcation point, and a hysteresis phenomenon as previously explained between $\tau_{\min }^{\prime}=6 \mathrm{~h}$ and $\tau_{\min }=9 \mathrm{~h}$ of residence time, correspond to a typical subcritical bifurcation $(49,50)$. The instability observed in the range $\left[\tau_{\min }^{\prime} ; \tau_{\min }\right]$ of residence time could then result in an oscillating stable limit cycle leading to the washing out of the PBR (trivial solution with $\left.<r_{X}>=0\right)$. 
Table 3. Comparison between model and experimental productivities in stable, steady-state continuous mode for different radiant incident fluxes $q_{R}$ and different residence times $\tau$ in the photobioreactor. The values of the working illuminated fraction $\gamma$ for experiments in physical limitation by light are respectively indicated.

\begin{tabular}{|c|c|c|c|c|}
\hline \multirow[b]{2}{*}{$\mathbf{q}_{\mathrm{R}}\left(\mathrm{W} \mathbf{m}^{-2}\right)$} & \multicolumn{2}{|c|}{$\begin{array}{l}\text { Stable kinetic regime } \\
\qquad(\gamma=1)\end{array}$} & \multicolumn{2}{|c|}{$\begin{array}{l}\text { Stable regime with physical limitation } \\
\text { by light }(\gamma<0.5)\end{array}$} \\
\hline & $\begin{array}{c}\text { Experimental } \\
\text { productivity } \\
{\left[\mathrm{kg} \mathrm{m}^{-3} \mathrm{~h}^{-1}\right]}\end{array}$ & $\begin{array}{c}\text { Model } \\
\text { productivity } \\
{\left[\mathrm{kg} \mathrm{m}^{-3} \mathbf{h}^{-1}\right]}\end{array}$ & $\begin{array}{c}\text { Experimental } \\
\text { productivity } \\
{\left[\mathrm{kg} \mathrm{m}^{-3} \mathbf{h}^{-1}\right]}\end{array}$ & $\begin{array}{c}\text { Model } \\
\text { productivity } \\
{\left[\mathrm{kg} \mathrm{m}^{-3} \mathbf{h}^{-1}\right]}\end{array}$ \\
\hline \multirow[b]{2}{*}{50} & \multirow{2}{*}{\multicolumn{2}{|c|}{$\mathrm{nd}$}} & $0.068 \pm 0.007$ & 0.062 \\
\hline & & & \multicolumn{2}{|c|}{$\tau=17 \mathrm{~h}(\gamma=0.195)$} \\
\hline \multirow[b]{2}{*}{100} & $0.042 \pm 0.005$ & 0.038 & $0.082 \pm 0.009$ & 0.083 \\
\hline & \multicolumn{2}{|c|}{$\tau=8.8 \mathrm{~h}$} & \multicolumn{2}{|c|}{$\tau=11.2(\gamma=0.276)$ and $23.8 \mathrm{~h}(\gamma=0.123)$} \\
\hline \multirow[b]{2}{*}{250} & $0.054 \pm 0.006$ & 0.052 & $0.119 \pm 0.012$ & 0.113 \\
\hline & \multicolumn{2}{|c|}{$\tau=11 \mathrm{~h}$} & \multicolumn{2}{|c|}{$\tau=12.5 \mathrm{~h}(\gamma=0.249)$} \\
\hline
\end{tabular}

The general behavior depicted in Fig. 2 at $q_{R}=100 \mathrm{~W} \mathrm{~m}^{-2}$ was confirmed by experiments at different incident light fluxes. For example, at $q_{R}=50 \mathrm{~W} \mathrm{~m}^{-2}$, the calculated critical residence time $\tau_{\min }$ was 10.5 $\mathrm{h}$, and so a cultivation with $\tau=17 \mathrm{~h}$ (higher residence time) gave a stable steady state at high productivity in accordance with the model calculation (Table 3). In the same way, an experiment was performed at $q_{R}=250 \mathrm{~W} \mathrm{~m}^{-2}$ with a calculated critical residence time $\tau_{\min }=11.5 \mathrm{~h}$. The residence time was initially kept at a low value affording a stable steady state in kinetic mode ( $\gamma=1$, Fig. 3$)$. It was then increased above the critical value $(\tau=12.5 \mathrm{~h})$, leading to an increase in productivity up to a maximum value, in close agreement with the model calculations (solid line, Fig. 3). Finally, the residence time was decreased under the critical value $(\tau=11.1 \mathrm{~h})$ to operate in the non-stable branch, leading to a rapid 
washing out of the PBR. From a metabolic point of view, it must be noted that the decrease in biomass growth rate is accompanied by the appearance of acetoacetate in the output flow of the PBR. This implies that this metabolite plays a crucial role in the metabolic deviations occurring on the non-stable branch of the stability diagram (Fig. 2). In all cases, it must be pointed out that experimental results are well predicted by model calculations, both for kinetic results (Table 3 and Fig. 3) and for stoichiometric results at stable steady state conditions under light limitation (Eqs. 11, 14 and Table 4). In addition, Table 4 clearly shows that the global stoichiometry is not sensitive to the PHB content changes since both experimental results and model calculations gave constant mass and molar conversion yields for acetate and $\mathrm{CO}_{2}$.

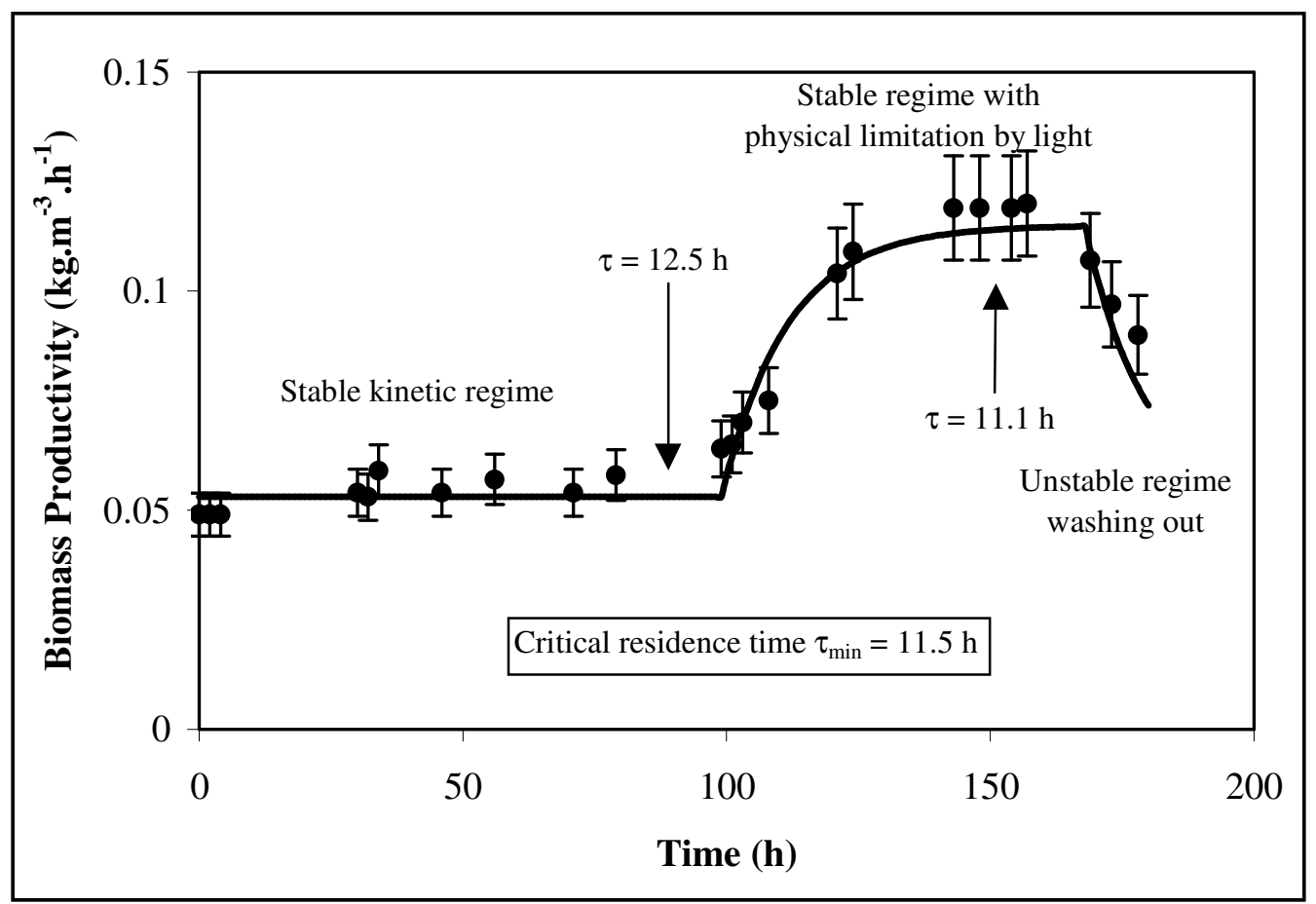

Figure 3. Comparison between model and experimental data for the biomass productivity obtained in a continuous photobioreactor illuminated at $q_{R}=250 \mathrm{~W} \mathrm{~m}^{-2}$. The residence time was slightly varied around the calculated critical value $\tau_{\min }=11.5 \mathrm{~h}$. From a stable kinetic regime, a higher value $(\tau=12.5$ h) provides the maximum productivity in light-limited condition, whereas a lower value $(\tau=11.1 \mathrm{~h})$ leads to the unstable domain, and to the washing out of the reactor. 


\section{Analysis of the second critical mode}

The stable behavior at high productivity under light transfer limitation is not observed at any residence time higher than the critical value $\tau_{\min }$. It has been experimentally observed in fact, that a second critical value $\tau_{\max }$ exists from which the PBR productivity begins to oscillate. The oscillating behavior has been typically observed on the biomass concentration in the output flow of the reactor, obtained at an incident radiant light flux $q_{R}$ of $100 \mathrm{~W} \mathrm{~m}^{-2}$ and with a constant residence time (Fig. 4). It appears at high biomass concentration, and then for low values of $\gamma(<0.1)$. Because the biomass productivity oscillates between the maximum value calculated by the model and the half of this maximum, one can postulate that this corresponds to an alternate inactivation of the dark operative volume ( $\beta$ fraction), probably linked to a photosystem regulation mechanism. This regulation also involves the acetoacetate as an intermediate metabolite, the oscillations of its concentration displaying a phase shift with the biomass concentration in the output of the PBR (data not shown). Thus it seems that as previously seen for the non-stable branch at low residence times, the acetoacetate production was concomitant with the inactivation of the dark operative volume in the PBR. However, for high biomass concentration and residence times, this volume was periodically restored, enabling the reactor productivity to oscillate. These metabolic changes were also accompanied by morphological changes of the cells because the trichome division was stopped, leading to very long filaments, and the motility of cells was lost. Similar sustained oscillations in cells concentration for continuous photoautotrophic cultures of Chlorella vulgaris were already reported (51) with also as a consequence, important changes in the division cycle of cells.

Practically, from Eqs. (9) and (13), it is easy to show that the alternate inactivation of the $\beta$ fraction can lead to periodic oscillations of the biomass concentration $C_{X}$ at constant residence time between the two boundary values: 


$$
\begin{aligned}
& C_{X \max }=\frac{1}{2} \tau<r_{X}>(1+\zeta) \\
& C_{X \min }=\frac{1}{2} \tau<r_{X}>(2-\zeta)
\end{aligned}
$$

where:

$$
\zeta=\left[1-\exp \left(-\frac{T}{\tau}\right)\right]
$$

is a damped factor to take into account that the steady state $C_{X_{\infty}}=\tau\left\langle r_{X}>\right.$ is never reached because of the existence of the semi-period $T$ for oscillating behavior. Likewise, noting that $\gamma=V_{3} / V_{T}$, one can rewrite Eq. (10) in light limitation as:

$$
<r_{X}>=f_{I} \frac{2}{V_{T}} \iiint_{V_{3}} r_{X 3} d V=f_{I} \frac{2}{V_{T}} I
$$

in which the integral $I$ does not depend on the biomass concentration $C_{X}$ or on the time $t$, and is only a function of the incident light flux $q_{R}$ and the reactor geometry, i.e., a constant. This makes it possible to integrate Eq. (13) over a semi-period of time $T$, and to combine with Eqs. (17-19) to obtain the general relation giving the asymptotic periodic time course for the biomass concentration:

$$
C_{X}(t)=f_{I} \frac{\tau}{V_{T}} I\left\{\frac{3}{2}+(-1)^{\left[\frac{t}{T}\right]-1}\left[\zeta e^{-\frac{1}{\tau}\left[t-\left(\left[\frac{t}{T}\right]-1\right) T\right]}-\frac{1}{2}\right]\right\}
$$

in which $\lceil x\rceil$ is the so-called ceiling function rounding the value of $x$ to the first higher integer, and where $(-1)^{\lceil x\rceil-1}$ is the square wave function.

Equation 20 has been used on Figure 4 with a semi-period $T=83 \mathrm{~h}$ (thick line) and then $\zeta=0.85$, to display the asymptotic periodic behavior of the biomass concentration in the output flow of the reactor, whereas the complete model (Eq. 13) was used to take into account the initial condition at a higher value 
of concentration when the residence time was changed (thin line). These results shows first that the asymptotic behavior is rapidly reached as early as the first period, and second that the model calculations are again in close agreement with the experimental data (Fig. 4). Moreover, if the value of $\zeta$ is assumed to be a constant, then Eq. (18) allows the calculation of the semi-period $T$ for any residence time $\tau$ in the PBR; however this needs to be verified by further experiments.

Table 4. Main stoichiometric results obtained in stable steady state continuous cultures at different radial incident light flux $q_{R}$ onto the photobioreactor. All the results hold for cultures under limitation by light energy transfer rate $(\gamma<0.5)$ corresponding to the domain of validity for the stoichiometric analysis (Eq. 14 in text).

\begin{tabular}{|c|c|c|c|c|c|c|c|c|}
\hline \multirow[t]{2}{*}{$\begin{array}{c}q_{R} \\
{\left[\mathrm{~W} \mathbf{m}^{-2}\right]}\end{array}$} & \multicolumn{2}{|c|}{ Global C-formula } & \multicolumn{2}{|c|}{$\begin{array}{c}\text { PHB mass fraction } \\
{[\%]}\end{array}$} & \multicolumn{2}{|c|}{$\begin{array}{l}\text { Biomass/Acetate } \\
\text { mass conversion } \\
\text { yield } Y_{X / S}[\mathrm{~kg} / \mathrm{kg}]\end{array}$} & \multicolumn{2}{|c|}{$\begin{array}{l}\text { Mole percentage of } \\
\text { evolved } \mathrm{CO}_{2} \text { in the } \\
\text { total produced } \\
\text { carbon }[\%]\end{array}$} \\
\hline & Experimental & Model & Experimental & Model & Experimental & Model & Experimental & Model \\
\hline 50 & $\begin{array}{c}\mathrm{CH}_{1.72} \\
\mathrm{O}_{0.35} \mathrm{~N}_{0.17} \\
\mathrm{~S}_{0.004} \\
\mathrm{P}_{0.010}\end{array}$ & $\begin{array}{c}\mathrm{CH}_{1.72} \\
\mathrm{O}_{0.36} \mathrm{~N}_{0.17} \\
\mathrm{~S}_{0.005} \\
\mathrm{P}_{0.012}\end{array}$ & $15 \pm 2$ & 12 & $0.65 \pm 0.06$ & 0.647 & $14 \pm 2$ & 13.0 \\
\hline 100 & $\begin{array}{c}\mathrm{CH}_{1.72} \\
\mathrm{O}_{0.38} \mathrm{~N}_{0.16} \\
\mathrm{~S}_{0.003} \\
\mathrm{P}_{0.009}\end{array}$ & $\begin{array}{c}\mathrm{CH}_{1.70} \\
\mathrm{O}_{0.37} \mathrm{~N}_{0.15} \\
\mathrm{~S}_{0.005} \\
\mathrm{P}_{0.011}\end{array}$ & $20 \pm 2$ & 20 & $0.64 \pm 0.06$ & 0.646 & $13 \pm 2$ & 12.9 \\
\hline 250 & $\begin{array}{c}\mathrm{CH}_{1.73} \\
\mathrm{O}_{0.36} \mathrm{~N}_{0.15} \\
\mathrm{~S}_{0.003} \\
\mathrm{P}_{0.008}\end{array}$ & $\begin{array}{c}\mathrm{CH}_{1.66} \\
\mathrm{O}_{0.40} \mathrm{~N}_{0.12} \\
\mathrm{~S}_{0.004} \\
\mathrm{P}_{0.009}\end{array}$ & $34 \pm 4$ & 36 & n.d. & 0.644 & $13 \pm 2$ & 12.5 \\
\hline 400 & n.d. & $\begin{array}{c}\mathrm{CH}_{163} \\
\mathrm{O}_{0.42} \mathrm{~N}_{0.10} \\
\mathrm{~S}_{0.003} \\
\mathrm{P}_{0.007}\end{array}$ & $49 \pm 5$ & 47 & $0.63 \pm 0.06$ & 0.643 & $12 \pm 2$ & 12.3 \\
\hline
\end{tabular}




\section{The pigment content regulation as a possible explanation}

As previously mentioned in the model descriptions, the coupling between light transfer, stoichiometry and kinetic rates depends strongly on the photosystem functioning in photoheterotrophic conditions. This functioning is intimately linked to a caught light regulation mechanism by cells, which vary their pigment content, i.e., the number and size of photosynthetic antennas.

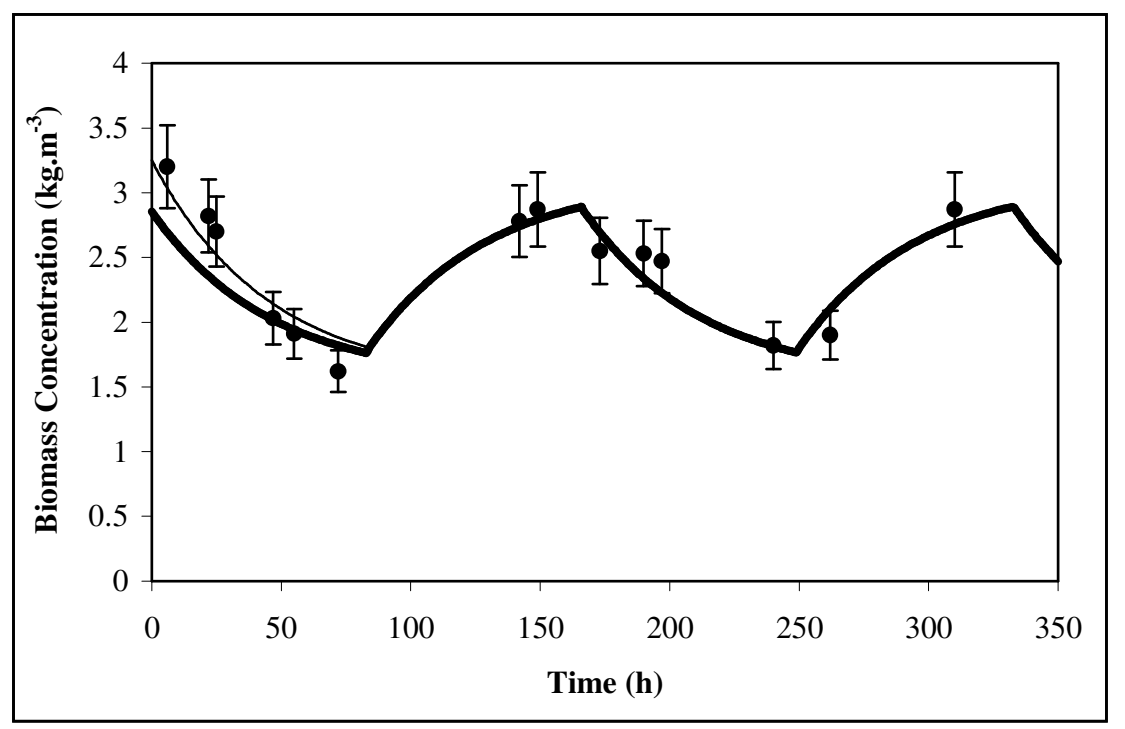

Figure 4. Comparison between experimental data and model for typical oscillations of the biomass concentration in the output flow of the photobioreactor. The conditions for the continuous culture were an incident light flux $q_{R}=100 \mathrm{~W} \mathrm{~m}^{-2}$ and a constant residence time $\tau=43.5 \mathrm{~h}$.

( — ) Actual model calculation from a given initial condition

( - Asymptotic oscillating behavior given by Equation (20)

Using Eq. (5) for light transfer, it is possible to obtain the variation in pigment content versus the biomass concentration in the PBR instead of the illuminated fraction $\gamma$, by model calculation (Eq. 12). This was done for an incident light flux $q_{R}$ of $100 \mathrm{~W} \mathrm{~m}^{-2}$ in Figure 5 showing a close agreement between experimental data and model calculations.

This figure gives some insight on the stability behavior in the PBR and could serve as a qualitative explanation of the pigment regulation mechanism. The first dashed line corresponds to the minimum 
critical residence time $\tau_{\text {min }}$, i.e. it appears that for biomass concentrations higher than $0.7 \mathrm{~kg} \mathrm{~m}^{-3}$ at this incident light flux, the productivity is stable and maximum because the PBR operates in light transfer limitation (Fig. 2). Likewise, the second dashed line at high concentration corresponds roughly to the appearance of the oscillating behavior for the productivity in the PBR. These two lines then define the three domains of functioning for the PBR. At low biomass concentration (below $\tau_{\min }$ ), the relation giving the pigment content is very sensitive and it is clear that a very small change in biomass concentration in the PBR involves a marked pigment content regulation mechanism for the photosystem, probably affecting the biomass growth rate. Moreover, in these conditions, the residence time in the PBR is short, which amplifies the effect of a decrease in growth rate, leading to a rapid decrease in biomass concentration, which in turn emphasizes the pigment content regulation that slackens the growth rate, and so on... Such a mechanism is probably responsible for the washing out of the PBR observed when operating in the unstable branch domain of Figure 2.

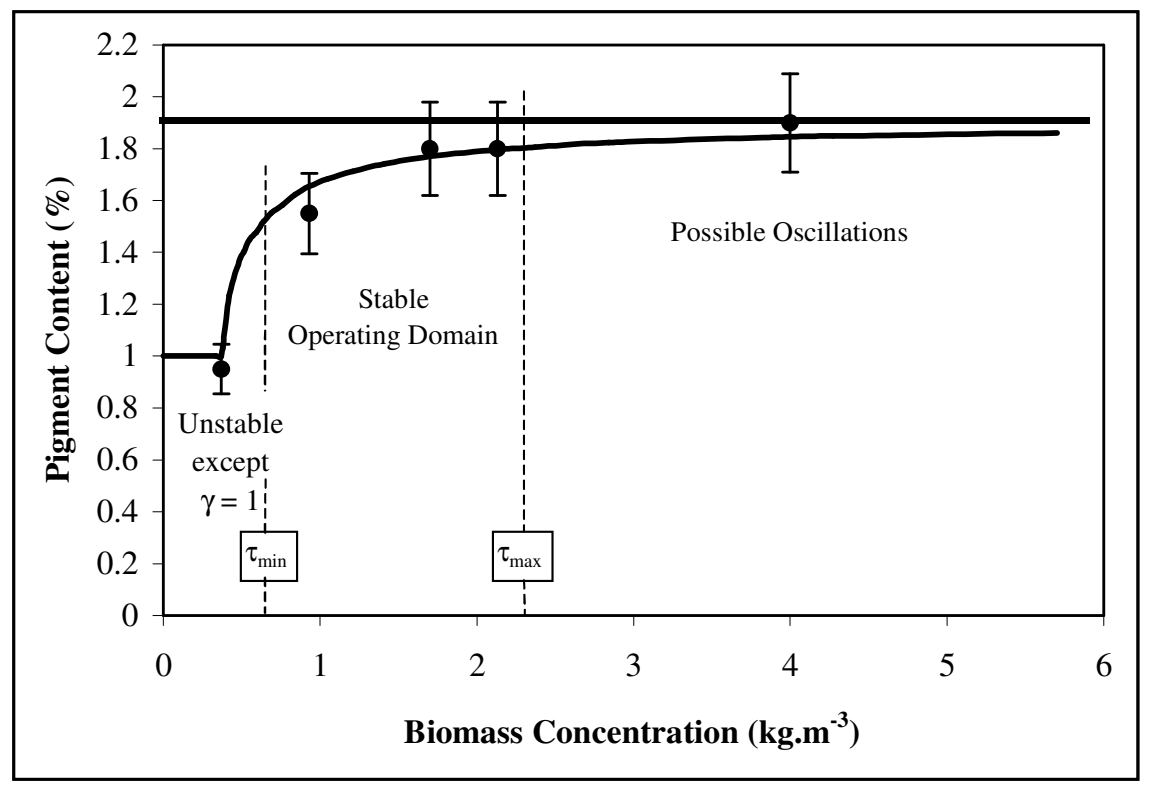

Figure 5. Comparison between model calculation and experimental data for the pigment content versus the biomass concentration in the photobioreactor. The results were obtained at a constant incident light flux $q_{R}=100 \mathrm{~W} \mathrm{~m}^{-2}$, and varying the residence time. The experimental points correspond to Figures 2 and 6 , and the two critical residence times are represented. 
Conversely, for biomass concentrations higher than $2.4 \mathrm{~kg} \mathrm{~m}^{-3}\left(\tau_{\max }\right)$, the relation between the pigment content and the biomass concentration in the PBR is not sensitive and is nearly a constant. For this reason the above adaptation mechanism becomes impossible, involving greater metabolic and morphologic changes in the cells as an oscillating growth rate. Consequently, the appearance of oscillating behavior in the PBR is defined in our model when the pigment content approaches its maximum asymptotic value, allowing the calculation of the value of the maximum critical residence time $\tau_{\max }$ leading to a stable maximum productivity for the PBR.

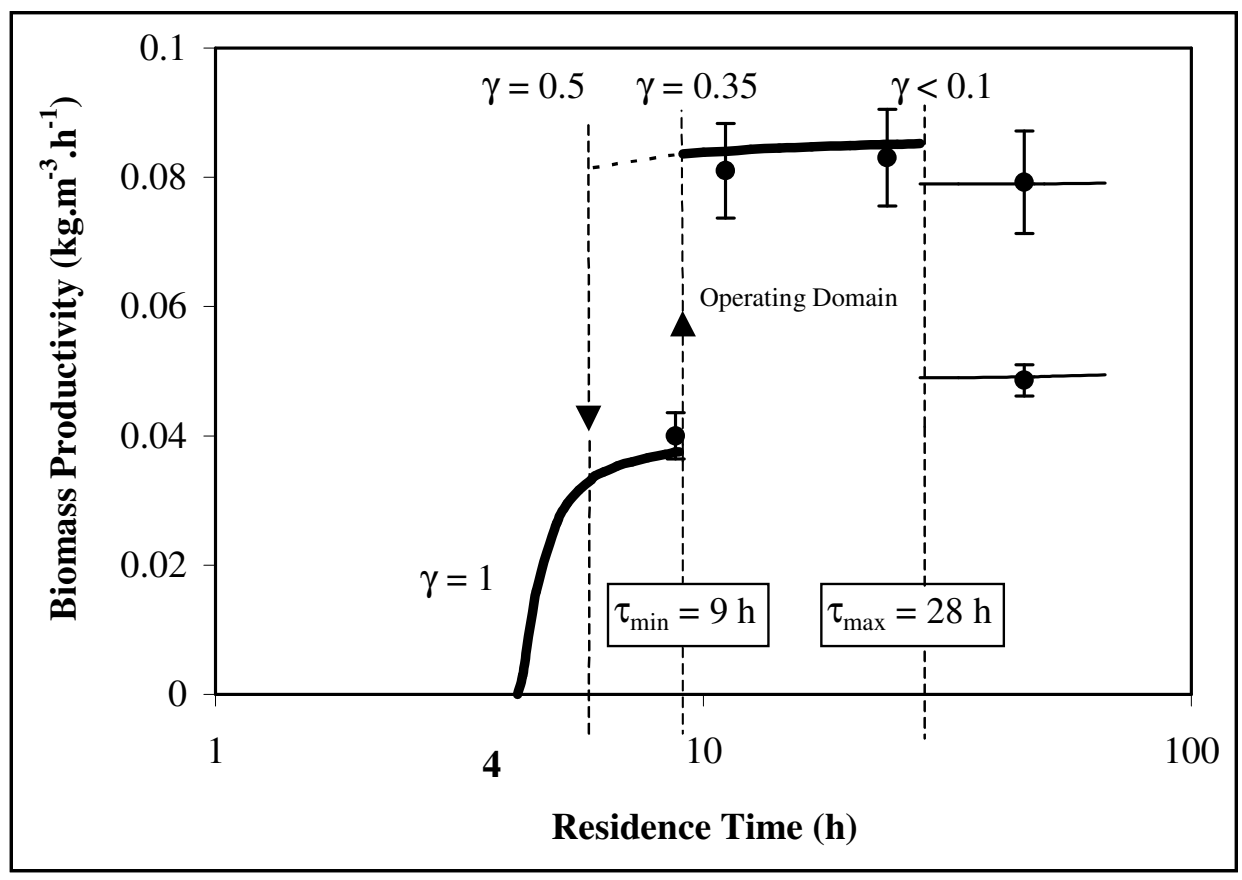

Figure 6. Complete stability diagram with the same conditions as Figure $2\left(q_{R}=100 \mathrm{~W} \mathrm{~m}^{-2}\right)$, but showing the appearance of the second critical residence time $\tau_{\max }$ with oscillating behavior. The comparison is made between experimental productivities and model calculations in this condition. The engineering operating domain between the two critical values is indicated.

( 1 ) Stable functioning for the PBR; ( - - . ) Unstable domain; ( - ) Oscillating behavior 
The model was then used to draw a complete diagram for the general behavior of a cylindrical PBR illuminated at a mean constant incident light flux of $100 \mathrm{~W} \mathrm{~m}^{-2}$ (Fig. 6). This includes a possible twopoints biomass concentration (given by Eq. 17) oscillating behavior from a calculated critical residence time $\tau_{\max }=28 \mathrm{~h}$. Experimental results obtained in each different set of conditions are in close agreement with these calculations but this needs to be confirmed by further experiments at other incident light fluxes in the operating domain $\left(1-300 \mathrm{~W} \mathrm{~m}^{-2}\right)$.

\section{The operating domain and control of the PBR}

For any engineering application using continuous cultures in PBR with Rs. rubrum in photoheterotrophic conditions, it is obviously desirable to define a stable domain with the highest productivity. From the analysis presented in this paper and for a given incident light flux, this operating domain ranges clearly between the two critical residence times $\tau_{\min }$ and $\tau_{\max }$ defined above (see Fig. 6).

Controlling the PBR by incident light flux is not a trivial procedure because operating in a chemostat can lead to biomass concentration changes and then to washing out or oscillating behavior. Likewise, operating in a turbidostat can lead to residence time changes with the same consequences. The best option is to work at constant working illuminated fraction $\gamma$, i.e. to operate in a "luminostat".

Because the numerical values of $\tau_{\min }$ and $\tau_{\max }$ strongly depend on the incident light flux $q_{R}$, the model was used with $q_{R}$ ranging between 1 and $300 \mathrm{~W} \mathrm{~m}^{-2}$ (operating domain without photoinhibition) in order to define the corresponding common values of $\gamma$ available at any incident flux onto the PBR. The results are very surprising and show a very narrow range for which $\gamma$ must remain at around $0.2 \pm 20 \%$ if it is desired to control the productivity over the total range of incident light flux $q_{R}$. Practically, this implies accurately measuring the mean incident light flux and the biomass concentration in the PBR, and then adapting the residence time in order to maintain the value of $\gamma$ at around 0.2 in all cases. This, of course, 
is only feasible by model-based predictive control (24), and requires having an accurate and sound knowledge description of the radiant light transfer in the PBR for $\gamma$ calculation, as proposed at the beginning of this paper (Eq. 5).

\section{CONCLUSIONS}

The new knowledge model presented in this paper appears well adapted to predict and simulate the apparently surprising regimes obtained for biomass productivity when the photoheterotrophic bacterium Rs. rubrum is cultivated in a continuous photobioreactor. In particular, its ability to calculate the minimum residence time corresponding to a sub-critical bifurcation for productivity, and splitting into stable and unstable domains the high productivity obtained in physical light transfer limitation has been proved. In the same manner, a method for the calculation of the maximum residence time leading to an oscillating behavior of the PBR is proposed and discussed, and the ability of the model to simulate the oscillations in biomass concentration has been checked. Stoichiometric aspects have also been investigated and a law proposed for the calculation of the PHB content inside the cells when the incident light flux onto the PBR is varied.

In addition, the predictive character of the proposed model is ensured by the fact that all the model coefficients for mean volumetric rate calculations can be theoretically computed from basic properties of any given micro-organism (shape, mean size, pigment content), and from more complicated TIP analyses for each kind of photosystem functioning existing in the microbial world.

However, further experiment are necessary to confirm the validity of the calculated critical residence times in many different conditions of light fluxes, flow rates and PBR geometries, especially for the appearance of the oscillating behavior. Important additional work also needs to be done on applying the thermodynamics of irreversible processes to the Rs. rubrum photosystem functioning in 
photoheterotrophic mode, in order to obtain more thorough knowledge of the pigment content regulation mechanism, together with a prediction of the PHB content changes from $\mathrm{P} / 2 \mathrm{e}^{-}$ratio calculations.

In its present form, however, the model can be used to set operating conditions for the main process variables (incident light flux, residence time), affording high and stable biomass productivities in a PBR. In the near future, it will be assessed in dynamic conditions as a tool for model-based predictive control of heterotrophic photobioreactors operating in continuous mode. 


\section{NOTATIONS}

a Mean volumetric absorption coefficient for the considered domain of wavelength $\left[\mathrm{m}^{-1}\right]$

A Local Volumetric Rate of radiant Energy Absorbed (LVREA) [ $\left.\mathrm{W} \mathrm{m}^{-3}\right]$

$b \quad$ Fraction of light back-scattered by micro-organisms [dimensionless]

$C_{X} \quad$ Biomass concentration $\left[\mathrm{kg} \mathrm{m}^{-3}\right]$

Ea Mean mass absorption coefficient for the considered domain of wavelength $\left[\mathrm{m}^{2} \mathrm{~kg}^{-1}\right]$

Es Mean mass scattering coefficient for the considered domain of wavelength $\left[\mathrm{m}^{2} \mathrm{~kg}^{-1}\right]$

$f_{I} \quad$ Illuminated surface fraction of the photobioreactor [dimensionless]

I Specific radiant light intensity for the considered domain of wavelength $\left[\mathrm{W} \mathrm{m}^{-2}\right]$

$I_{\Sigma} \quad$ Total radiant light energy over $4 \pi$ steradians for the considered domain of wavelength $\quad\left[\mathrm{W} \mathrm{m}^{-2}\right.$ ]

$I_{\text {Emin }}$ Minimal radiant energy available by photosynthesis in photoheterotrophic conditions [W $\mathrm{m}^{-2}$ ]

$K \quad$ Half saturation constant for light energetic yield conversion $\quad\left[\mathrm{W} \mathrm{m}^{-2}\right]$

$N \quad$ Rotation speed $\left[\mathrm{s}^{-1}\right]$

$p \quad$ Normalized phase function for scattering [dimensionless]

q Radiant light energy flux for the considered domain of wavelength [W $\left.\mathrm{m}^{-2}\right]$

$q_{R} \quad$ Mean radial incident light flux on the reactor for the considered domain of wavelength $\quad\left[\mathrm{W} \mathrm{m}{ }^{-2}\right.$ ]

$r$ Radius [m]

$R \quad$ Radius of the photobioreactor $[\mathrm{m}]$

$r_{X} \quad$ Volumetric biomass growth rate $\left[\mathrm{kg} \mathrm{m}^{-3} \mathrm{~h}^{-1}\right]$

$s \quad$ Mean volumetric scattering coefficient for the considered domain of wavelength $\left[\mathrm{m}^{-1}\right]$

$t \quad$ Time [h]

$t_{c} \quad$ Cycle time for cells $\quad[\mathrm{s}]$

$t_{d} \quad$ Dark inefficient residence time for cells [s]

$t_{l} \quad$ Light residence time for cells $[\mathrm{s}]$

$t_{m} \quad$ Mixing time in the reactor $[\mathrm{s}]$

$T \quad$ Semi-period for oscillations [h]

u, u' Unit vectors [dimensionless]

$V \quad$ Volume $\left[\mathrm{m}^{3}\right]$

$V_{T} \quad$ Total volume of the photobioreactor $\left[\mathrm{m}^{3}\right]$ 
$w_{P H B}$ Mass fraction for PHB in total biomass [dimensionless]

$w_{P I G}$ Mass fraction for pigments in total biomass [dimensionless]

$x_{P H B}$ Mole fraction for PHB in total biomass [dimensionless]

$Y_{X / S}$ Biomass/Acetate mass conversion yield $\quad\left[\mathrm{kg}_{\text {biomass }} \mathrm{kg}_{\text {acetate }}{ }^{-1}\right]$

\section{Greek Letters}

$\alpha \quad$ Lumped parameter for optical radiative properties of the medium [dimensionless]

$\beta \quad$ Fraction for dark operative volume in the photobioreactor [dimensionless]

$\gamma \quad$ Fraction for working illuminated volume in the photobioreactor [dimensionless]

$\delta \quad$ Length constant characterizing the light transfer $\left[\mathrm{m}^{-1}\right]$

$\theta \quad$ Angle $[\mathrm{rad}]$

$\zeta$ Damped factor [dimensionless]

$\rho \quad$ Energetic yield for photon conversion [dimensionless]

$\rho_{M} \quad$ Maximum energetic yield for photon conversion [dimensionless]

$\tau \quad$ Residence time [h]

$\tau_{\min }$ Critical minimum residence time [h]

$\tau_{\max }$ Critical maximum residence time $[\mathrm{h}]$

$\bar{\psi} \quad$ Mean mass stoichiometric quantum yield for the considered domain of wavelength $\quad\left[\mathrm{kg} \mathrm{J}^{-1}\right]$

$\omega \quad$ Solid angle $[\mathrm{sr}]$

\section{Averaged Quantities}

$$
\begin{array}{ll}
\widehat{x}=2 \pi \int_{0}^{\frac{\pi}{2}} x \sin \theta d \theta \text { or } 2 \pi \int_{\frac{\pi}{2}}^{\pi} x \sin \theta d \theta & \text { hemispherical averaging } \\
\bar{x}=\frac{1}{\Delta t} \int_{\Delta t} x d t & \text { time averaging } \\
<x>=\frac{1}{V} \iiint_{V} x d V & \text { spatial averaging }
\end{array}
$$




\section{REFERENCES}

(1) Kobayashi, M.; Fujii, K.; Shimamoto, I.; Maki, T. Treatment and reuse of industrial waste water by phototrophic bacteria. Progress Water Technol. 1979, 11, 279-294.

(2) Poughon, L.; Gros, J-B.; Dussap, C-G. MELiSSA loop: first estimates of flow rates and concentrations through the loop. $30^{\text {th }}$ International Congress on Environmental Systems, Toulouse, France, July 10-13, 2000. SAE paper 2380.

(3) Brandl, H.; Gross, R. A.; Lenz, R. W.; Lloyd, R.; Fuller, R. C. The accumulation of poly(3hydroxyalkanoates) in Rhodobacter sphaeroides. Arch. Microbiol. 1991, 155, 337-340.

(4) Liebergesell, M.; Hustede, E.; Timm, A.; Steinbuchel, A.; Fuller, R.C.; Lenz, R. W.; Schlegel, H. G. Formation of poly(3-hydroxyalkanoates) by phototrophic and chemolitotrophic bacteria. Arch. Microbiol. 1991, 155, 415-421.

(5) Hashimoto, K.; Tsuboi, H.; Iwasaki, S.; Shirai, Y. Effect of $\mathrm{pH}$ on the production of poly- $\beta$ hydroxybutyrate by photosynthetic bacteria Rhodospirillum rubrum. J. Chem. Eng. Japan. 1993, $26,56-58$.

(6) Hustede, E.; Steinbuchel, A.; Schlegel, H. G. Relationship between the photoproduction of hydrogen and the accumulation of PHB in non-sulphur purple bacteria. Appl. Microbiol. Biotechnol. 1993, 39, 87-93.

(7) Vrati, S.; Verma, J. Production of molecular hydrogen and single cell protein by Rhodopseudomonas capsulata from cow dung. J. Ferm. Technol. 1983, 61, 157-162.

(8) Vrati, S. Single cell protein production by photosynthetic bacteria grown on the clarified effluents of biogas plant. Appl. Microbiol. Biotechnol. 1984, 19, 199-202.

(9) Kobayashi, M. Waste remediation and treatment using anoxygenic phototrophic bacteria. In Anoxygenic Photosynthetic Bacteria; Blankenship, R. E., Madigan, M. T., Bauer, C. E., Eds.; Kluwer Academic Publishers, the Netherlands, 1995; pp 1269-1282.

(10) Tsygankov, A. A.; Hyrata, Y.; Miyake, M.; Asada, Y.; Miyake, J. Photobioreactor with photosynthetic bacteria immobilized on porous glass for hydrogen photoproduction. J. Ferm. Bioeng. 1994, 77, 575-578.

(11) Yetis, M.; Gündüz, U.; Eroglu, I.; Yücel, M.; Türker, L. Photoproduction of hydrogen from sugar refinery wastewater by Rhodobacter sphaeroides O.U. 001. Int. J. Hydrogen Energy. 2000, $25,1035-1041$.

(12) Barbosa, M. J.; Rocha, J. M. S.; Tramper, J.; Wijffels, R. H. Acetate as carbon source for hydrogen production by photosynthetic bacteria. J. Biotechnol. 2001, 85, 25-33.

(13) Molina Grima, E.; Garcia Camacho, F.; Sanchez Perez, J. E.; Fernandez Sevilla, J. M.; Acién Fernandez, F. G.; Contreras Gomez, A. A mathematical model of microalgal growth in light limited chemostat culture. J. Chem. Tech. Biotechnol. 1994, 61, 167-173.

(14) Rorrer, G. L.; Mullikin, R. K. Modeling and simulation of a tubular recycle photobioreactor for macroalgal cell suspension culture. Chem. Eng. Science. 1999, 54, 3153-3162. 
(15) Molina Grima E.; Fernandez, J.; Acién, F. G.; Chisti, Y. Tubular photobioreactor design for algal cultures. J. Biotechnol. 2001, 92, 113-131.

(16) Tsygankov, A. A. Laboratory scale photobioreactors. Appl. Biochem. Microbiol. 2001, 37, 333341.

(17) Wu, X.; Merchuk, J. C. A model integrating fluid dynamics in photosynthesis and photoinhibition processes. Chem. Eng. Science. 2001, 56, 3527-3538.

(18) Pruvost, J.; Legrand, J.; Legentilhomme, P.; Muller-Feuga, A. Simulation of microalgae growth in limiting light conditions - flow effect. A.I.Ch.E. J. 2002, 48, 1109-1120.

(19) Cornet, J-F.; Dussap, C-G.; Dubertret, G. A structured model for simulation of cultures of the cyanobacterium Spirulina platensis in photobioreactors: I. Coupling between light transfer and growth kinetics. Biotech. Bioeng. 1992, 40, 817-825.

(20) Cornet, J-F.; Dussap, C-G.; Gros, J-B.; Binois, C.; Lasseur, C. A simplified monodimensional approach for modeling coupling between radiant light transfer and growth kinetics in photobioreactors. Chem. Eng. Science. 1995, 50, 1489-1500.

(21) Cornet, J-F.; Dussap, C-G.; Gros, J-B. Kinetics and energetics of photosynthetic microorganisms in photobioreactors. Adv. Biochem. Eng./Biotechnol. 1998, 59, 153-224.

(22) Aiba, S. Growth kinetics of photosynthetic microorganisms. Adv. Biochem. Eng. 1982, 23, 85156.

(23) Cornet, J-F.; Dussap, C-G.; Gros, J-B. Conversion of radiant light energy in photobioreactors. A.I.Ch.E. J. 1994, 40, 1055-1066.

(24) Cornet, J-F.; Dussap, C-G.; Leclercq, J-J. Simulation, design and model based predictive control of photobioreactors. In Focus on Biotechnology; Hofman, H., Thonart, P., Eds.; Kluwer academic publishers: Dordrecht, 2001; Vol. 4, pp 227-238.

(25) Muller Feuga, A.; Le Guedes, R.; Pruvost, J. Contributions and limits of modeling for optimization of Porphyridium cruentum cultures in annular photobioreactor. J. Appl. Phycol. $\mathbf{2 0 0 3}$, in press.

(26) Dussap C-G. Etude thermodynamique et cinétique de la production de polysaccharides microbiens par fermentation en limitation par le transfert d'oxygène. Modèle structuré de la production de xanthane. Thèse de Doctorat ès Sciences Physiques, Université Blaise Pascal, Clermont-Ferrand, France, 1988, n ${ }^{\circ} 409$.

(27) Van de Hulst, H. C. Light scattering by small particles. Dover Publications Inc., $2^{\text {nd }}$ ed. 1981.

(28) Bohren, C. F.; Huffman, D. R. Absorption and scattering of light by small particles. John Wiley and Sons Inc., New York, , 1983.

(29) Segers, L.; Verstraete, W. Conversion of organic acids to $\mathrm{H}_{2}$ by Rhodospirillaceae to grown with glutamate or dinitrogen as nitrogen source. Biotech. Bioeng. 1983, 25, 2843-2853.

(30) Suhaimi, M.; Liessens, J.; Verstaete, W. $\mathrm{NH}_{4}{ }^{+}-\mathrm{N}$ assimilation by Rhodobacter capsulatus ATCC 23782 grown axenically and non-axenically in $\mathrm{N}$ and $\mathrm{C}$ rich media. J. Appl. Bacteriol. 1987, 62, 53-64. 
(31) Cornet, J-F.; Marty, A.; Gros, J-B. Revised technique for the determination of mean incident light fluxes on photobioreactors. Biotechnol. Prog. 1997, 13, 408-415.

(32) Vernon, L. P.; Garcia, A. F. Pigment-Protein complexes derived from Rhodospirillum rubrum chromatophores by enzymatic digestion. Biochim. Biophys. Acta. 1967, 143, 144-153.

(33) Braunegg, G.; Sonnleitner, R.; Lafferty, M. A rapid gas chromatographic method for the determination of poly- $\beta$-hydroxybutyric acid in microbial biomass. Eur. J. Appl. Microbiol. Biotechnol. 1978, 6, 29-37.

(34) Herbert, D.; Phillips, P. J.; Strange, R. E. Chemical analysis of microbial cells. Meth. Microbiol. 1971, 5b, 209-394.

(35) Brewster, M. Q.; Tien, C. L. Examination of the two-flux model for radiative transfer in particular systems. Int. J. Heat Mass Transfer. 1982, 25, 1905-1907.

(36) Koenigsdorff, R.; Miller, F.; Ziegler, R. Calculation of scattering fractions for use in radiative flux models. Int. J. Heat Mass Transfer. 1991, 34, 2673-2676.

(37) Schuster, A. Radiation through a foggy atmosphere. Astrophys. J. 1901, 21, 1-22.

(38) Favier-Teodorescu, L.; Pons, A.; Poughon, L. Stoichiometric analysis of Rhodospirillum rubrum growth on different carbon substrates. Technical Note 45.4, ESA/ESTEC Contract 13323/98/NL/MV. 1999.

(39) Stucki, J. W. Stability analysis of biochemical systems - A practical guide. Prog. Biophys. Molec. Biol. 1978, 33, 99-187.

(40) Roels, J. A. Energetics and Kinetics in Biotechnology. Elsevier biomedical press, Amsterdam, 1983.

(41) Bejan, A. Advanced Engineering Thermodynamics. John Wiley and Sons Inc., New York, 1988.

(42) Badescu, V. Thermodynamics of Solar Energy Conversion into Work. In Thermodynamics of Energy Conversion and Transport; Seniutycz, S., De Vos, A., Eds.; Springer Verlag: New York, 2000; pp 14-48.

(43) Paillotin, G. Etude théorique des modes de création, de transport et d'utilisation de l'énergie d'excitation électronique chez les plantes supérieures. Thèse de Doctorat ès Sciences, Université Paris XI - Orsay, France, 1974, n 1380.

(44) Cornet, J-F.; Albiol, J. Modeling photoheterotrophic growth kinetics of Rhodospirillum rubrum in rectangular photobioreactors. Biotechnol. Prog. 2000, 16, 199-207.

(45) Favier-Teodorescu, L.; Cornet, J-F.; Dussap, C-G. Modelling continuous culture of Rhodospirillum rubrum in photobioreactor under light limited conditions. Biotechnol. Letters. 2003, 25, 359-364.

(46) Cornet, J.-F. Etude cinétique et énergetique d'un photobioreacteur. Thèse de Doctorat. Université Paris XI Orsay, France, 1992, nº 1989.

(47) Nagata, S. Mixing, principles and applications. John Wiley and Sons Inc., New York, 1975.

(48) Barbosa, M. J.; Janssen, M.; Ham, N.; Tramper, J.; Wijffels, R. H. Microalgae cultivation in airlift reactors: modeling biomass yield and growth rate as a function of mixing frequency. Biotechnol. Bioeng. 2003, 82, 170-179. 
(49) Bergé, P.; Pomeau, Y.; Vidal, C. L’ordre dans le chaos. Hermann, Paris, $2^{\text {nd }}$ ed. 1988.

(50) Thompson, J. M. T.; Stewart, H. B. Nonlinear dynamics and chaos. John Wiley and Sons Ltd, New York, $7^{\text {th }}$ ed. 1991.

(51) Javanmardian, M.; Palsson, B. O. Continuous photoautotrophic cultures of the eukaryotic alga Chlorella vulgaris can exhibit stable oscillatory dynamics. Biotechnol. Bioeng. 1992, 39, 487-497.

\section{ACKNOWLEDGMENTS}

The authors thank Mr. David Duchez for his technical assistance in the experiments. This work was supported by the European Space Agency (ESA) through the MELiSSA Project. 